\title{
Recent Advances in Dental Composites: An Overview
}

\author{
Dara Lavanya1 ${ }^{1,}$, Divya Buchi ${ }^{1}$, Satyanaryana Raju Mantena ${ }^{2}$, Madhu Varma $\mathbf{K}^{3}$, \\ D. Bheemalingeswara Rao ${ }^{2}$, Vinay Chandrappa ${ }^{4}$
}

${ }^{1}$ Undergraduate student, Vishnu Dental College, Bhimavaram, Andhra Pradesh, India.

2Professor, Department of Prosthodontics and Implantology, Vishnu Dental College, Bhimavaram, Andhra Pradesh, India.

3Professor, Department of Conservative Dentistry and Endodontics, Vishnu Dental College, Bhimavaram, Andhra Pradesh, India.

4Professor, Department of Pedodontics and Preventive Dentistry, Vishnu Dental College, Bhimavaram, Andhra Pradesh, India.

\section{N F O R M A T I O N}

\section{Article History}

Received 06 November 2019

Accepted 12 November 2019

Available online

15 November 2019

K E Y W O R D S

\section{A B S T R A C T}

Composite resins are widely used aesthetic materials in restorative dentistry. These materials were introduced to overcome the inherent shortcomings of amalgam restorative materials. Dental amalgams are unesthetic and toxic. Earlier composites lack in mechanical properties to withstand the masticatory forces. Various filler particles have been added to composite resins to improve their physical and mechanical properties. Filled composite resins exhibit high compressive strength, abrasion resistance, ease of application and high translucency. Depending on the filler size and shapes, various composites have been developed until now. This article is a review of numerous types of composites that are technologically advanced to modify their properties.

\section{Introduction}

Composites

Fillers

Condensable composites

Flowable composites

Nanocomposites

Self-adhering composites

Fibre reinforced composites.
The acrylic resin was introduced to the dental profession in the mid-1950's, and it replaced the silicate cement soon from the dentistry as a direct aesthetic restorative material. Since their introduction, acrylic-based materials have continued to play a significant role in restorative and prosthetic dentistry [1 3]. The advantages of these acrylic resins include tooth-like appearance, ease of manipulation insolubility in oral fluids, and low cost. However, these materials could not accomplish the requirements of restorative materials as they undergo considerable shrinkage during the polymerization process leading to marginal leakage. In addition, they were having poor wear resistance, high water sorption, and a high coefficient of thermal expansion. Quartz powder was incorporated as a filler to address the inherent drawbacks of the resins. These fillers occupy the spaces between the polymer chains and improve the physical and mechanical properties, which are primarily influenced by the volume fraction of inert fillers [1-5]. However, the early composites were lack of proper bonding between the polymeric resin and the filler particles. In 1962, Dr L. Bowen invented a new dimethacrylate resin, such as Bisphenol A Glycidyl methacrylate (Bis-GMA) and an organosilane coupling agent, which provides a bond between filler particles and the resin matrix [4-6]. This invention led to the evolution in resin-based direct aesthetic restorative materials.

Correspondence: *Corresponding author Email Address: dara.lavanya178@gmail.com.

How to cite this article: Lavnya D, Divya B, Mantena SR, Madhu Varma K, Bheemalingeswara Rao D, Chandrappa V. Recent Advances in Dental Composites: An Overview. Int J Dent Mater 2019;1(2): 48-54.

DOI: http://dx.doi.org/10.37983/IJDM.2019.1202 
Composite resins are complex, tooth-colored filling materials that offer excellent esthetic potential and acceptable longevity without the need for extensive tooth preparation, allowing minimally invasive preparation or sometimes no preparation at all. They represent one of many success of modern biomaterial research. However, the early formulations of these resin composite materials had numerous drawbacks such as poor handling characteristics and polymerization shrinkage. To address this, various types of filler particles with different volume fractions have experimented with the resins. This led to the development of maco-filled, small-filled, micro-filled and hybrid composites [4]. Although, these materials showed better improvements compared to earlier versions but not up to the standard. The quest of researchers on improving its properties led to the development of newer versions of composite resins. Therefore, this review focused on discussing various composite resin materials developed in recent years.

\section{Recent advances in composites}

\subsection{Condensable composites or packable composites or polymer rigid Inorganic ma- trix material (PRIMM)}

These are one of the new advancements in posterior composites, developed by Dr Lars Ehrnford of Sweden in 1995. This system is composed of a resin matrix and an inorganic ceramic component. Unlike in conventional composites; in this system, the resin is incorporated into the fibrous ceramic filler network rather than including the filler particles into the composite resin matrix. The filler mainly consists of Aluminium oxide, Silicon oxide glass particles or barium aluminium silicate or strontium glasses. Further, colloidal silica ultrafine particles are also incorporated to control the handling characteristics such as viscosity, resistance to flow, condensability and reduced stickiness [7].

The glass particles are liquified to a molten state, and it is forced through a die to form thin strands of glass fibers with a diameter of approximately 2-3 micrometres. These glass fibers are then reheated to an adequate temperature after pulverizing them into small space particles. This results in the superficial fusion of glass fibers at selected sites (silanation) and forms a continuous network of small chambers or cavities with 2-micrometre dimensions. Resin is then allowed to infiltrate into these spaces or chambers. This concept provides a basis for fabricating packable or condensable posterior composite resin resulted in advantages of better reproduction of occlusal anatomy, better marginal adaptation, ease in achieving a good contact point [8]. The physical and mechanical behaviour of these materials is better than that of hybrid-composites and similar to that of silver amalgam [9]. However, the clinical performance of these materials is identical to that of the hybrid composites [5,10,11]. Condensable composites are indicated in class II cavities.

\subsection{Indirect composite resins}

The indirect composites such as inlay and onlay systems were developed to address the major clinical problems associated with the direct posterior composite resins. The first generation indirect composite resins were introduced in the 1980s by Touti and Mörmann. Indirect composite resin restorations exhibit superior marginal adaptation, contour, and proximal contact as it is fabricated on a die rather than directly in the cavity preparation $[4,8]$. The number of highly improved indirect resin restorative systems have been introduced with unusually good properties like wear resistance, esthetics, control over polymerization shrinkage, and marginal adaptation [4].

\subsection{Organically modified ceramic oligomers (ORMOCER)}

ORMOCER is an acronym for organically modified ceramics. They are considered to be molecule-sized hybrid structures consisting of inorganic, organic copolymers. Organic reactive monomers are bound to inorganic -si-o-si- network. These molecular hybrids consist of, for example, methacrylate-terminated chains grafted on to a central cyclic polysilioxane $2-3 \mathrm{~nm}$ particles. These nanoparticles are dispersed on a molecular scale $[2,12]$. These are high molecular weight, flexible, relatively low viscosity crosslinking molecules. The large spacing between crosslinks resulting from curing produces a low-level polymerization shrinkage, while the inorganic network provides abrasion resistance through its glass-like structure and low water sorption due to its hydrophobicity $[2,12,13]$.

Because of their unique composition, ORMOCER-based dental materials offer characteristic advantages in comparison to conventional composites. They include; 
limited cure shrinkage, very high biocompatibility, good manipulation properties, and excellent esthetics. These materials are indicated for class-I to $\mathrm{V}$ cavities, veneering of discoloured anteriors, repair of veneers, core build-up, orthodontic bonding adhesive, indirect inlays, and reconstruction of traumatically affected anteriors $[2,12]$.

\subsection{Fiber Reinforced Composites (FRC)}

Fiber reinforcement has further increased the potential uses of composites within restorative dentistry. Glass fibers, carbon fibers polyethylene fibers, aramid fibers, etc., are the most commonly used fibers in dental composites [3]. These fibers can be oriented in different directions; unidirectional, weave type, mesh type, etc., in the resin matrix to improve the physical and mechanical properties of composites. The durability of the fiber-reinforced composites mainly depends on essential factors including fiber loading within the resin, adhesion of fibers to the matrix, the orientation of fibers, volume of fibers in composite matrix, etc., [3]. Silane coupling agents are commonly used to provide bonding between resin matrix and fibers [6]. These fiber reinforced composites have shown improved strength and stiffness and improved wear resistance. Their main applications are in periodontal splinting/ post-trauma splint, fixed partial dentures, reinforcing or repairing dentures, fixed orthodontic retainers, root posts, and reinforced biomedical implants $[3,14]$. Mohan $\mathrm{M}$ et al. (2019) compared the fracture toughness of fiber-reinforced composites with micro-hybrid and nano-hybrid composites. They also reported that the FRCs exhibited more fracture toughness compared to the other materials. They also suggested that these are the choice of the restorative materials for posterior teeth [15].

\subsection{Flowable Composites}

These composites were developed mainly to improve the handling properties for composites resins. These composites contain less filler content of traditional hybrid composites with the same filler size. The resin matrix was increased to reduce the viscosity of the mixture. Since the filler content was reduced, they lack adequate strength to withstand high stresses [16] Due to increase in resin content; these composites show more polymerization shrinkage [16] and less elastic moduli and its use in high-stress bearing areas is questionable [17-19]. However, these materials wet the tooth surface better and flows easily into the every undercuts and also forms in thin layers reducing the formation of air pockets at the tooth-restoration interface $[16,20]$. In addition, flowable composites exhibit superior chemical curing properties compared to the conventional composites.this is because of their lower filler loading which would decrease the light scattering through material and provide a better degree of conversion depth. Further, these materials contain a germanium based photoinitiator which is more effective and has a much higher significant yield compared to camphorquinone amine system [21]. Baoudi $\mathrm{K}$ et al. (2015) suggested in a systematic review that the flowable composites are the promising aesthetic restorative materials for the future and will become markedly useful material in various aesthetic restorative procedures [22].

\subsection{Self-healing or self-repairing compo- sites}

Materials usually have a limited shelf-life and degrade over time due to different physical, chemical or biological stimuli. But researchers have developed materials which can repair themselves. The self-healing and selfrepairing composite is an epoxy-based system which contains resin-filled microcapsules. These microcapsules may be destroyed and release the resin when the epoxy resin undergoes crazing. The resin subsequently fills these cracks and reacts with a Grubb's Catalyst that is dispersed in the epoxy composite. This may eventually polymerize the resin and repair the crack [23].

\subsection{Stimuli response materials}

These are also called "smart materials". The properties of these materials essentially depend on external stimulus such as temperature, $\mathrm{pH}$, mechanical stress, moisture, etc., These composite materials release fluoride, calcium, and hydroxyl ions into the surroundings of the filling depending on the $\mathrm{pH}$. These materials release, especially when the $\mathrm{pH}$ is less than 5.5 , a significant number of ions than that at the neutral $\mathrm{pH}$. Therefore, it provides additional caries protection [23-25].

\subsection{Bellglass HP}

Bellglass HP is an indirect restorative material which was introduced in 1996 by Belle de St. Claire. These materials have increased polymerization rate as they 
are cured under pressure (29 PSI) at an elevated temperature of $1380 \mathrm{C}$ and in the presence of nitrogen gas. The elevated temperature and the increased atmospheric pressure not only increases the rate of curing but also reduces vaporization potential of the monomers. Wear resistance of the Bellglass HP is increased due to curing in the presence of nitrogen gas. In addition, the rate of curing is also improved as nitrogen gas provides an oxygen-free environment. Oxygen acts as polymerization inhibitor and delays the polymerization reaction and also reduces the translucency of composites [26, 27].

\subsection{Self-adhering composites}

Self-adhering composites are also called as compobonds. Self-adhering flowable composite combines the advantages of both dental adhesives and restorative materials technologies (8th generation) in a single product [28]. The first compo-bond was introduced in 2009 by (Kerr Corp). Compo-bonds have the benefits of self-etching dentin bonding agents and nano-filled resins. They eliminate the precursory bonding stage necessary to adhere, resin to tooth substrate, thus reducing the chances of postoperative sensitivity. These composites have properties similar to the conventional flowable composites. They also have the properties of 7 th generation of dentin bonding agents; thus, they act as shock absorbers beneath the resin-based composite restoration. As compo-bonds function both as dentin adhesive and resin restorative both as dentin adhesive and resin restorative material, a longer curing time is necessary to ensure that both constitutes are fully polymerized [29].

\subsection{Art glass}

Art glass is a nonconventional dental polymer marketed since 1999. It is widely used in making indirect restorations such as inlays, onlays, and crowns. These materials exhibit improved wear resistance and other physical and mechanical properties due to the greater level of crosslinking. The fillers used are radiopaque Barium glass with an average particle size of $0.7 \mathrm{mi}-$ crometres and colloidal silica, which enhance the handling characteristics to a greater extent. A special light curing unit such as Xenon stroboscopic light-curing device with the emission ranges from $300-500 \mathrm{~nm}$ is used for curing of these resins. The advantages of these materials include high wear resistance compared to traditional composites, good marginal adaptation, est- hetics, and superior proximal contact $[26,27]$.

\subsection{Nanocomposites}

Nanotechnology consists of reducing components of material to nanometric scale for use in a new material, to improve the final characteristics. In nano-filled resins, the inorganic nano-fillers are added to organic resin matrix to have the strength of inorganic material and flexibility and toughness of organic material [30,31]. These composites have approximately $60 \%$ volume filler loading, making the nano-filled resins as strong as the hybrid and micro-hybrid resins. The nanocomposites have nanofillers that contain nanomodifier such as the nanomers and nanoclusters that result in increased flexural strength, increased modulus of elasticity, improved wear resistance and hardness, decreased polymerization shrinkage and enhance polishability of resin. Nanofillers may include colloidal silica or ormocers, such as Inceram X from Dentsply. Similar particles may be used in resin-based bonding systems. Nanoparticle filled dental particles may show an enhanced fracture toughness and adhesion to tooth tissue $[2,4,30,31]$.

Nano filled, and nanohybrids are commonly available nanocomposites. The average particle size of Nanofilled ranges from 1-100 $\mathrm{nm}$, whereas nanohybrids are comprised of larger particles of ranging from 0.4 to 5 microns. The properties of these composites are size and shape determinant. These nanofillers present superior properties than nanohybrids $[1,30]$.

\subsection{Antimicrobial materials}

Antimicrobial agents and antibiotics were introduced into composites to provide antimicrobial activity $[24,32]$. Recently, antimicrobial nanoparticles such as quaternary ammonium polyethylenimine [24,32], Silver [33-36], Zinc Oxide [37-39], Titania [40] and Chitosan [41] nanoparticles were experimented with composites to impart antimicrobial characteristics. Microbes may be killed on direct contact with these materials or through leaching of the antimicrobial materials into the oral environment. Silver and Titania particles are commonly used into dental particles to increase antimicrobial property and enhance biocompatibility. Fatemeh K et al. (2017) reported that the adhesives incorporated with silver nanoparticles showed greater bond strength. However, it was also reported that the bond strength was dependent on the 
composition of the adhesive resins [36].

\subsection{Calcium phosphate nanoparticles}

Calcium phosphate such as Hydroxyapatite phosphate, anhydrous calcium phosphate, tetra calcium phosphate and dicalcium phosphate anhydrous have been used as fillers. To make mineral releasing dental composites. The incorporation of these particles improves stress-bearing capacity and ion release that inhibit dental caries $[42,43]$.

\subsection{Bioactive glass nanoparticles}

These have excellent regenerative properties in mineralised tissues. The high surface area of nanoparticles may facilitate the dissolution of ions from the gas and thus accelerate dentin mineralization. These nanoparticles induce the formation of apatite in dentin [44].

\section{Conclusion}

The science and technology of composites have significantly improved compared with their predecessors. Although composites have not evolved to the point of totally replacing amalgam, they have become a viable substitute for amalgam in many clinical situations. As we know the development of high-performance restorative materials is essential to the success of dental treatment but with composite resin materials, problems still exist. However, new expanding resins, nanofiller technology, and improved bonding systems have the potential to reduce these problems. With increased patient demands for esthetics, the use of composite materials for restorations will continue to grow; and so will the area of research to combat the existing limitations of composites as a restorative material.

\section{References}

1. Anusavice KJ. Restorative Resins (in) Philips' Science of Dental Materials. Elsevier, India. 11th edition. 399-442.

2. Rama Krishna Alla. Restorative Materials: Composite Resins, (In) Dental Materials Science, Jaypee Brothers Medical Publishers (P) Ltd, New Delhi, India 2013; 130-48.
3. Alla RK, Sajjan S, Ramaraju AV, Ginjupalli K, Upadhya $\mathrm{N}$, Influence of fibre reinforcement on properties of Denture base resins, J Biomater Nanobiotech, 2013;4(1): 91-97.

4. Ravi RK, Rama Krishna Alla, Shammas M, Devarhubli A, Dental Composite - A Versatile Restorative Material: An Overview, Ind J Dent Sci., 2013; 5(5):111-115.

5. Hervás-García A, Martínez-Lozano MA, CabanesVila J, Barjau-Escribano A, Fos-Galve P. Compositeresins. A review of the materials and clinical indications. Med Oral Patol Oral Cir Bucal 2006; 11:215-20.

6. Konakanchi A, Alla RK, Guduri V. Silane Coupling Agents - Benevolent Binders in Composites, Trends Biomater. Artif. Organs, 2017; 31(3): 102107.

7. Faras R, Pujar M, Lahiri A, Havaldar SC, Shetye SA. Recent advances in composite resins - A review. Paripex-Ind J Res. 2018;7(8): 93-94.

8. Prachi Singh, Nitesh Kumar, Richa Singh, Kamini Kiran, Shailesh Kumar. Overview and recent advances in composite resin: A review. Int J Sci Stud. 2015; 3(9): 169-172.

9. Suzuki S. Does the wear resistance of packable composite equal that of dental amalgam?. J Esthet Restor Dent 2004;16:355-65.

10. de Souza FB, Guimaraes RP, Silva CH. A clinical evaluation of packable and microhybrid resin composite restorations: one-year report. Quintessence Int. 2005;36:41.

11. Benly P. Recent Advances in Composite - A Review. J Pharm Sci Res. 2016;8(8): 881-883

12. Sivakumar A, Valiathan A. Dental Ceramics and Ormocer Technology - Navigating the future, Trends Biomater Artif Organs 2006; 20: 40-3.

13. Leinfelder KF. New developments in resin restorative systems. J Am Dent Assoc 1997; 128: 573-81.

14. Freilich MA, Meiers JC, Duncan JP, Goldberg AJ. Fibrereinforced Composite in Clinical Dentistry. Chicago: Quintessence Publishing Co., Inc.; 2000.

15. Mohan M, Ramciya KV, Justin Baby. Comparison of Fracture Resistance of Teeth Restored with Microhybrid, Fiber Reinforced And Nanohybrid Composite Resins An In-Vitro Study. Int J Recent Sci Res. 2019:10(08):34460-34465.

16. Olmez A, Oztas N, Bodur H. The effect of flowable resin composite on microleakage and internal voids in class II composite restorations. Oper Dent 2004;29:713-9. 
17. Cohen R. The expanded use of improved flowable composite. Dent Town, 2008; 64: 25-35.

18. Attar N, Tam LE, McComb D. Flow, strength, stiffness and radiopacity of flowable resin composites. J Can Dent Assoc, 2003; 69: 516-21.

19. Jai Ganesh I, Vasanthakumari A, Vivek Reddy, Vivek K, Lokesh S. Revolutionary excellence of composite resins - A review. WJPMR. 2018,4(9), 116119.

20. Gupta R, Tomer AK, Kumari A, Perle N, Chauhan P, Rana S. Recent advances in bulkfill flowable composite resins: A review. Int J App Dent Sci. 2017;3 (3):79-81.

21. Jaya Singh, Rajkumar B, Boruah LC, Gupta V, Akanksha Batt. Bulk fill composites in dentistry- A review. Ind J Conser Endodont. 2019;4(1):9-13.

22. Baroudi K, Rodrigues JC, Flowable Resin Composites: A Systematic Review and Clinical Considerations, J Clinical Diagnos Res. 2015:9(6): ZE18ZE24

23. Badami V, Ahuja B. Biosmart materials: Breaking new ground in dentistry. Sci World J. 2014: 986912.

24. Yeli M, Kidiyoor KH, Nain B, Kumar P. Recent advances in composite resins - A review. J Oral Res Rev. 2010;2:8-14.

25. Jandt KD, Sigusch BW. Future perspectives of resin-based dental materials. Dent Mater 2009; 25: 1001-1006.

26. Nandini S. Indirect resin composites. J Conserv Dent, 2010; 13: 184-94.

27. Lutz F, Phillips RW. A classification and evaluation of composite resin systems. J Prosthet Dent, 1983;50: 480-8.

28. Shaalan 00, Abou-Auf E, El Zoghby AF. Clinical evaluation of self-adhering flowable composite versus conventional flowable composite in conservative Class I cavities: Randomized controlled trial. J Cons Dent. 2018;21(5):485.

29. D’Alpino P.H.P., da Rocha Svizero N., Carrilho M. (2018) Self-Adhering Composites. In: Miletic V. (eds) Dental Composite Materials for Direct Restorations. Springer, Cham.

30. Mitra SB, Wu D, Holmes BN. An application of nanotechnology in advanced dental materials. J Am Dent Assoc. 2003;134(10):1382-90.

31. Beun S, Glorieux T, Devaux J, Vreven J, Leloup G. Characterization of nanofilled compared to universal and microfilled composites. Dent Mater. 2007;23(1):51-9
32. Beyth N, Yudovin-Farber I, Bahir R, Domb AJ, Weiss EI. Antibacterial activity of dental composites containing quaternary ammonium polyethylenimine nanoparticles against Streptococcus mutans. Biomaterials 2006;27:3995-4002

33. das Neves PBA, Agnelli JAM, Kurachi C, de Souza CWO. Addition of Silver nanoparticles to composite resin: Effect on Physical and Bactericidal Properties In Vitro. Braz Dent J. 2014; 25(2):141-145.

34. Farahani A, Beyrami A, Piri H, Naghizadeh A, Imani H, Farahani MH. Evaluation of Antibacterial Properties of Resin Composites Containing Silver Nanoparticles on Streptococcus Mutans. J Dent Oral Health. 2018; 5: 1-6.

35. Ai M, Du Z, Zhu S, Geng H, Zhang X, Cai Q, Yang X. Composite resin reinforced with silver nanoparticles-laden hydroxyapatite nanowires for dental application. Dent Mater. 2017;33(1):12-22.

36. Fatemeh K, Mohammad Javad M, Samaneh K. The effect of silver nanoparticles on composite shear bond strength to dentin with different adhesion protocols. J App Oral Sci. 2017;25(4):367-73.

37. Sevinç BA, Hanley L. Antibacterial Activity of Dental Composites Containing Zinc Oxide Nanoparticles. J Biomed Mater Res. B. Appl Biomater. 2010; 94(1): 22-31.

38. Hojati ST, Alaghemand H, Hamze F, Babaki FA, Rajab-Nia R, Rezvani MB, Kaviani M, Atai M. Antibacterial, physical and mechanical properties of flowable resin composites containing zinc oxide nanoparticles. Dent Mater. 2013;29(5):495-505.

39. Angel Villegas N, Silvero Compagnucci MJ, Sainz Ajá M, Rocca DM, Becerra MC, Fabián Molina G, Palma SD. Novel Antibacterial Resin-Based Filling Material Containing Nanoparticles for the Potential One-Step Treatment of Caries. Journal of healthcare engineering. 2019; Article ID 6367919, 8 pages.

40. Sodagar A, Akhoundi MS, Bahador A, Jalali YF, Behzadi Z, Elhaminejad F, Mirhashemi AH. Effect of TiO2 nanoparticles incorporation on antibacterial properties and shear bond strength of dental composite used in Orthodontics. Dental Press Journal of Orthodontics. 2017;22(5):67-74.

41. Sodagar A, Bahador A, Jalali YF, Gorjizadeh F, Baghaeian P. Effect of Chitosan Nanoparticles Incorporation on Antibacterial Properties and Shear Bond Strength of Dental Composite Used in Orthodontics. Iran J Ortho. https://doi. org/10.17795/ ijo-7281. 2016. 
42. Xu HH, Moreau JL, Sun L, Chow LC. Nanocomposite containing amorphous calcium phosphate nanoparticles for caries inhibition. Dental Materials. 2011 Aug 1;27(8):762-9.

43. Xie XJ, Xing D, Wang L, Zhou H, Weir MD, Bai YX, $\mathrm{Xu} \mathrm{HH}$. Novel rechargeable calcium phosphate nanoparticle-containing orthodontic cement. International journal of oral science. 2017;9(1):24.

44. Polini A, Bai H, Tomsia AP. Dental applications of nanostructured bioactive glass and its composites. Wiley Interdisciplinary Reviews: Nanomedicine and Nanobiotechnology. 2013;5(4):399-410. 